\title{
EMPREENDEDORISMO FEMININO NO ARTESANATO:
}

\section{Uma análise crítica do caso das rendeiras dos Morros da Mariana}

\section{1- Marina Dantas de Figueiredo*}

Doutora em Administração pela Universidade Federal do Rio Grande do Sul (PPGA/UFRGS), Brasil.

Professora do Programa de Pós-Graduação em Administração de Empresas da Universidade de Fortaleza (PPGA/UNIFOR), Brasil.

marina.dantas@unifor.br

http://lattes.cnpq.br/0548529050384069

\section{2- Auristela do Nascimento Melo}

Mestre em Administração pela Universidade de Fortaleza (PPGA/UNIFOR), Brasil.

Professora do Instituto Federal do Piauí, Campus Parnaíba (IFPI), Brasil

auristela.melo@fapparnaiba.com.br

http://lattes.cnpq.br/4494781386318134

\section{3- Fátima Regina Ney Matos}

Doutora em Administração pela Universidade Federal de Pernambuco (PPGA/UFPE), Brasil.

Professora do Programa de Pós-Graduação em Administração de Empresas da Universidade de Fortaleza (PPGA/UNIFOR), Brasil.

fneymatos@globo.com

http://lattes.cnpq.br/5977512127210432

\section{4- Diego Queiroz Machado}

Doutorando em Administração pela Universidade de Fortaleza (PPGA/UNIFOR), Brasil.

Centro de Ciências da Comunicação e Gestão - Universidade de Fortaleza (PPGA/UNIFOR), Brasil.

diegoqueirozm@yahoo.com.br

http://lattes.cnpq.br/6926348689036257 


\title{
EMPREENDEDORISMO FEMININO NO ARTESANATO: UMA ANÁLISE CRÍTICA DO CASO DAS RENDEIRAS DOS MORROS DA MARIANA, PIAUÍ ${ }^{1}$
}

\section{RESUMO}

O artigo busca problematizar o empreendedorismo feminino a partir de uma perspectiva crítica, subsidiada por teorias feministas baseadas na relação entre trabalho e práticas sociais. O objetivo é compreender como a ação empreendedora pode contribuir para a emancipação feminina. A complexidade do estudo reside no objeto de pesquisa escolhido, qual seja as iniciativas empreendedoras de mulheres dedicadas a atividades artesanais. Por meio de um estudo de caso, exploram-se as causas e consequências da ação das empreendedoras reunidas na Associação de Rendeiras dos Morros da Mariana, com sua produção de rendas de bilro no município de llha Grande, Piauí, a partir do viés das relações de poder de gênero. Os achados do estudo apontam para a vinculação entre o desempenho da atividade artesanal das rendeiras e o reforço dos papeis de gênero tradicionais. Como conclusão, tem-se que mesmo que a produção e comercialização da renda sejam fontes geradoras de recursos para as mulheres da Associação, a atividade empreendedora baseada no artesanato não é uma ação emancipatória, capaz de subverter a desigual distribuição de poder de gênero na sociedade em questão. Recomenda-se, a partir dessa conclusão, a realização de outros estudos que tomem como objeto a atividade empreendedora feminina baseada em atividades artesanais tradicionais.

\section{Palavras-Chave}

Empreendedorismo feminino; Gênero; Artesanato; Perspectiva crítica; Associação de Rendeiras dos Morros da Mariana.

\section{FEMALE ENTREPRENEURSHIP IN CRAFTWORK: A CRITICAL ANALYSIS OF MORROS DA MARIANA LACE MAKERS CASE, IN PIAUI}

\begin{abstract}
This article aims to discuss female entrepreneurship from a critical perspective, supported by feminist theories based on the relationship between work and social practices. The objective is to understand how female entrepreneurial action can lead to female emancipation. The complexity of the study relies on the chosen research object, which is the entrepreneurial initiatives of woman that work with craft activities. Through a case study, we explore the causes and consequences of the actions of the entrepreneurs organized in the Lace-Makers Association of Morros da Mariana, that produces bilro lace in the city of Ilha Grande, Piauí, through the standpoint of power relations and gender. The research finding points out the link between lace-maker's artisanal activities and the reinforcement of traditional gender roles. As a conclusion, we acknowledged that even if production and the sales of lace may be a source of incomes for the group of woman drown together in the Association, the entrepreneurial activity based on craft is not an emancipator act that can subvert the unequal power distribution between man and woman in society. Following this conclusion, we recommend that further studies should take as research object the female entrepreneurial activity based on traditional craftwork.
\end{abstract}

\section{Keywords}

Female entrepreneurship; Gender; Craftwork; Critical perspective; Lace-Makers Association of Morros da Mariana. 


\section{Introdução}

O interesse por estudos relacionados à atividade empreendedora feminina tem crescido na academia internacional na mesma proporção em que aumenta a participação das mulheres na geração de emprego e renda no Brasil e no mundo (Cassol; Silveira; Hoeltgebaum, 2007; Lewis, 2006). Dada a natureza das mudanças do papel da mulher na sociedade ocidental contemporânea e as peculiaridades associadas à condição feminina em diferentes contextos locais, questões importantes afloram como objetos de investigação. No campo dos estudos sobre empreendedorismo feminino, são comuns os trabalhos que enfatizam as diferenças entre os gêneros para explicar o potencial inovador da entrada das mulheres no mercado de trabalho na condição de empreendedoras. São relativamente numerosos os estudos que examinam características psicológicas e sociais das empreendedoras (Bird \& Brush, 2002; Busenitz, West, Shepherd, Nelson, Chandler \& Zacharakis, 2003; Moore e Buttner, 1997), que justificam inovações organizacionais a partir de um estilo feminino de gestão (Blake \& Hanson, 2005; Macedo et al., 2004) ou buscam mapear as experiências de mulheres que, ao criarem ou assumirem a liderança de seus próprios negócios, inovam, transpondo a barreira simbólica que dificulta a ascensão das mulheres aos níveis mais altos da administração empresarial (Bush, 1992; Godwin, Stevens \& Brenner, 2006; Morrison, White \& Van Velsor, 1987; Munhoz, 2000).

Apesar de avançarem no entendimento do trabalho feminino e de adotarem uma perspectiva claramente incentivadora à atividade empreendedora feminina, é possível notar que a maior parte dos estudos sobre empreendedorismo feminino não problematiza - e até mesmo naturaliza - a desigual distribuição de poder entre homens e mulheres. É forte a tendência a tratar os rendimentos da atividade empreendedora feminina como complementar à renda familiar (Machado, 2009; Menezes \& Bertucci, 2009), assumindo-se que cabe ao homem o papel de provedor do lar e/ou que o trabalho feminino deve necessariamente ser devotado à família. No mesmo sentido, alguns analistas do empreendedorismo feminino também creditam às mulheres um estilo singular de administrar, fruto de um aprendizado originado na infância sobre valores, comportamentos e interesses tipicamente femininos (Hirsch \& Peters, 2004; Munhoz, 2000; Nunes, 2006).

Percebe-se, portanto, reduzido potencial crítico de estudos que reproduzem irrefletidamente preconceitos de gênero e, dessa forma, contribuem para que a atividade empreendedora feminina não seja emancipadora. Também é digno de nota o fato de que, no campo dos estudos sobre empreendedorismo, a emancipação - tanto para homens quanto para mulheres - seja resultado imediato do impacto econômico da atividade empreendedora, o que exclui do escopo da reflexão as outras tantas formas de submissão que persistem apesar da geração de renda e da melhoria do padrão de vida econômico (Calás, Smircich \& Bourne, 2009; Marquesan \& Figueiredo, 2014; Rindova; Barry; Ketchen, 2009). Nesse sentido, o presente artigo se propõe a problematizar o empreendedorismo feminino a partir de uma perspectiva crítica, subsidiada por teorias feministas que tomam por princípio a relação entre trabalho, práticas sociais e empreendedorismo (Calás, Smircich \& Bourne, 2007; 2009; Hurley, 1999; Mirchandani, 1999).

A complexidade do presente estudo - aquilo que nos permitirá explorar as relações imbricadas entre gênero e distribuição de poder - reside no objeto de pesquisa escolhido; qual seja, as iniciativas empreendedoras de mulheres dedicadas a atividades artesanais. Isso porque as práticas artesanais trazem em seu ensejo questões específicas da tradicional divisão sexual e social do trabalho, cuja análise crítica pode fazer com que o empreendedorismo feminino no artesanato seja uma contradição de termos. Por contradição de termos, entende-se uma operação linguística que aproxima dois conceitos dificilmente conciliáveis - neste caso, empreendedorismo feminino e atividade artesanal.

A questão de pesquisa que norteia nosso estudo é: como a ação empreendedora feminina, a partir do trabalho artesanal, pode contribuir para a emancipação das artesãs empreendedoras? 0 lócus da nossa investigação é o município de llha Grande, no Piauí, onde a produção caseira e familiar de renda de bilro, que existe desde o século XIX, vem sendo transformada em empreendimento comercial. Através de um estudo de caso, exploraremos as causas e consequências da ação das empreendedoras reunidas na Associação de Rendeiras dos Morros da Mariana a partir do viés das relações de poder de gênero.

Nas próximas seções, faremos uma exposição das teorias sobre empreendedorismo feminino, adotando uma perspectiva reflexiva crítica. A seguir, descreveremos a relação entre trabalho feminino e artesanato, a fim de elucidar como o empreendedorismo feminino no artesanato pode ser uma contradição de termos, dado o status subalterno das práticas femininas tradicionais. Depois, apresentaremos o caso das empreendedoras da Associação de Rendeiras dos Morros da Mariana, a partir do qual poderemos refletir sobre a atividade empreendedora no artesanato a partir de uma perspectiva de gênero. Por fim, a análise dos dados empíricos à luz das teorias que dão sustentação 
a este trabalho será fundamental para que possamos expor nossas conclusões e apontar a contribuição deste trabalho para o campo dos estudos sobre empreendedorismo.

\section{Quadro Teórico}

\subsection{Perspectiva Crítica: uma Lacuna na Teoria sobre Empreendedorismo Feminino}

Para a perspectiva feminista marxista, o trabalho constitui a dimensão mais relevante na análise do fenômeno do gênero (Blake \& Hanson, 2005; Holmstrom, 2002; Saffioti, 1976, 1985). Essa linha de pensamento defende que, na elaboração social das categorias de gênero, as diferenças entre homens e mulheres não devem ser tomadas apenas como variáveis ideológicas, sem eficácia na produção, mas, ao contrário, precisam ser encaradas como fenômenos cujas raízes se incrustam não apenas na ideologia patriarcal, mas no núcleo econômico do modo de produção capitalista industrial (Blake \& Hanson, 2005). A definição das identidades masculinas e femininas está fechada nas estruturas de classe, por sua vez forjadas na divisão social do trabalho. Para o pensamento feminista marxista, essas identidades são construídas por meio das práticas sociais do trabalho, nas quais "poder e sexualidade estão entrelaçados" (Calás \& Smircich, 2006, p. 292). Em síntese, o feminismo marxista analisa as funções das categorias de gênero no domínio da produção, da reprodução, da sexualidade e da socialização.

A questão da distribuição do trabalho social se fundamenta na dificuldade do capital em equalizar a força de trabalho e dissolver eixos estruturadores de hierarquias e desigualdades de acesso ao poder. Sendo parte do processo histórico, o capital não tem alcance suficiente para equalizar todas as forças de trabalho, subsistindo internamente ao capitalismo a diferença no valor do trabalho de grupos sociais distintos em termos de gênero, etnia e classe social. Com efeito, a projeção de Marx de que o capital teria direito sobre a igualdade na exploração da força de trabalho não se realizou em nenhuma sociedade, dadas as condições históricas de subordinação das mulheres e outros (Calás, Smircich \& Bourne, 2009).

A história não registra um só caso de sociedade que tenha organizado o trabalho doméstico em moldes distintos daqueles elaborados no seio do patriarcalismo. Basta registrar que nenhuma sociedade capitalista (e até socialista) conseguiu satisfazer à demanda por creches, conditio sine qua non para uma eventual equalização de todas as forças de trabalho (Holmstrom, 2002). A obrigação do trabalho feminino na esfera doméstica está intimamente relacionada à atual divisão sexual do trabalho, que segrega as mulheres em ocupações menos valorizadas socialmente e pior remuneradas. No âmago das relações de poder de gênero e classe, as mulheres podem tentar mudar as práticas correntes, mas sua capacidade subversiva está limitada por uma subordinação incorporada, que ganha às feições de inferioridade natural. Na medida em que membros dominantes nesses relacionamentos procuram reproduzir o que os beneficia, eles também contribuem para a criação de práticas sociais que, em sua institucionalização, adquirem a aparência de inevitabilidade.

Para dar seguimento a essa questão, cabe esclarecer que a família patriarcal compreende o padrão identificado como hegemônico para a organização social capitalista. Herança dos sistemas socioeconômicos anteriores, notadamente a escravidão, a família patriarcal predominou, ainda que diferenças nas relações entre gêneros e no trato das questões étnicas tenham propiciado organizações familiares diversas. O fato da pluralidade de arranjos familiares ter se resumido às características do modelo que representava a vida das camadas senhoriais demonstra a importância desse grupo na sociedade, constituída como sua imagem. Decorre que a subordinação da mulher está inserida em uma relação dialética mais ampla, que abrange a tensão entre aqueles que impõem de uma determinada estrutura de poder e aqueles que resistem a ela de maneira subliminar e pacífica. As questões concernentes à participação da mulher no mercado de trabalho e a importância do artesanato como ocupação feminina não se restringem, portanto, à distribuição de poder entre os sexos, mas também evidenciam que a organização da família patriarcal como ideal instituiu, na prática, a marginalização de formas de organização social alternativas ao padrão hegemônico.

Enquanto o sexo é, indiscutivelmente, um fato natural, o gênero é construído através das relações sociais. Diante dessa afirmação, pontua-se que certos atributos femininos são constructos sociais com causas históricas. Entre os séculos XVIII e XIX, os desdobramentos das revoluções burguesas impactaram profundamente a organização familiar. A relação conjugal modificou-se, visto que o antigo casamento por contrato não era conveniente aos ideais libertários e igualitários e o casamento por amor instituiu uma nova sensibilidade que mudaria radicalmente as feições da família em todo mundo ocidental (Moura \& Araujo, 2004). O período também determina uma nova relação de maternidade, na qual a criança passa a ser alvo privilegiado da atenção feminina (Badinter, 1985). Articulando-se aos interesses políticos e econômicos do Estado e aos interesses militares e religiosos, a sacralização do lar burguês impôs a ampliação do controle sobre os hábitos 
de todos os membros da família e lançou luzes sobre a penumbra da vida doméstica. Relações outrora restritas à esfera privada passaram a ser alvo de interesse social (Donzelot, 1986) num movimento que enalteceu o labor feminino e, ao mesmo tempo, sobrecarregou a mulher de mais funções domésticas. A crescente valorização da mulher-mãe, a rainha do lar, veio na esteira da valorização do devotamento e do sacrifício feminino em prol dos filhos e da família que surgiram no discurso médico e filosófico do período como inerentes à natureza da mulher.

Assumindo como foco principal as contradições fundamentais da sociedade brasileira, firma-se, conforme Saffioti (1984), a existência de três identidades sociais básicas: a de gênero, a de raça/etnia e a de classe social. Cabe mencionar, conforme os propósitos desse trabalho, que a identificação da operária como mulher trabalhadora explicita duas dimensões importantes da sua identidade: primeiro, o gênero, definidor de uma heterogeneidade de práticas sociais e políticas que caracterizam as mulheres na sociedade; e segundo, a ocupação que reflete o tipo de inserção das mulheres na estrutura de classes.

\subsection{Artesanato e Trabalho Feminino}

Os estudos sobre artesanato comumente revelam a grande participação feminina no processo produtivo (Fischer \& Soares, 2012). Por isso, o artesanato é campo útil para situarmos o lugar da mulher na esfera pública que corresponde ao mundo do trabalho. Isso porque a atividade se encontra hoje em uma encruzilhada conceitual, ora associada a um tipo de produção material exposta ao reconhecimento público e passível de comercialização, ora relacionada a um saber vivencial, recolhido ao domínio privado do indivíduo. O atual interesse em transformar o artesanato em um setor produtivo da economia (PAB, 2010), ao mesmo tempo em que coloca a produção artesanal na pauta de debates públicos, também suscita dúvidas a respeito da representatividade da atividade na organização do trabalho no Brasil. Paralelamente, o entendimento explícito ou velado do artesanato como atividade não produtiva, economicamente irrelevante e necessariamente reclusa à esfera privada induz a associação negativa com o trabalho feminino, que mormente sofre dos mesmos estigmas sociais (Fine, 1992; Rees, 1992).

Se a produção capitalista contemporânea se caracteriza pela intensa mecanização e emprego frequente da tecnologia, a atividade artesanal que subsiste atualmente guarda estreita semelhança com a produção pré-capitalista. É fato inconteste que a atividade tenha baixo grau de importância na atual configuração econômica, o que fica expresso, por exemplo, no valor monetário de muitos produtos artesanais e no fato das propostas desenvolvimentistas não atribuírem à manufatura forte impacto sobre o desenvolvimento das economias nacionais. No contexto contemporâneo, em que o princípio da utilidade foi substituído pelo princípio do consumo e a produção foi transformada em processo para a manutenção das necessidades humanas (Arendt, 2009), a atividade artesanal, outrora, dedicada à produção de objetos duráveis, dotados de utilidade e sentido intrínsecos, restringiu-se, em muitos casos, ao valor da tradição. Sob esse ponto de vista, a participação da mulher no artesanato, bem como o status inferior da atividade na economia atual dizem respeito às relações de poder e dominação que se perpetuam através do trabalho.

A associação entre o artesanato e o trabalho feminino pode ser interpretada como a consequência de uma mudança histórica abrangente, que decorre das alterações nas condições de produção a partir da consolidação do modo de produção capitalista em escala internacional. Para explorar essa questão, cujas implicações nos ajudam a compreender o status do artesanato na sociedade contemporânea e a participação feminina nesta atividade, convém esclarecer como o fenômeno da industrialização impactou as formas de produção, transformou as ferramentas (então artesanais) da manufatura e alterou a organização do trabalho. No capitalismo industrial, as relações de produção foram substancialmente modificadas se comparadas aos sistemas até então dominantes, notadamente o capitalismo mercantil. A esses acontecimentos corresponde o que Sennett (2008) entendeu ser o declínio da técnica ou a sistemática desvalorização dos saberes e da perícia artesanais que, outrora, estavam restritos às guildas de artesãos, caracterizadas como domínios de um fazer masculino.

Sennett (2008) propõe que não foram tanto as mudanças tecnológicas que alteraram as formas como os artesãos se relacionavam com o trabalho, visto que o emprego de ferramentas e mesmo de máquinas é até hoje verificável em atividades tradicionalmente identificadas como artesanais. O problema que se instituiu, segundo o autor, foi a perda da propriedade sobre os meios de produção e a drástica redução da autonomia profissional. Forçados pelas transformações sociais e econômicas do período, aprendizes e mestres de ofício passaram a engrossar a massa assalariada, em um novo processo de mobilidade social (Sennett, 2008). Esse movimento implicou a desvalorização do saber fazer e dos traços primordiais do artesanato, outrora transmitidas por artífices que se empenhavam em comunicar os segredos da produção, de geração em geração. 0 
decréscimo de importância do artesanato e a descaracterização deste sistema de produção a partir do século XVIII ocasionaram a evasão da força de trabalho masculina e sua paulatina substituição pela força de trabalho feminina.

Embora as mulheres tenham adentrado o mundo do trabalho ainda na primeira Revolução Industrial, é possível constatar que elas até hoje não participam maciçamente da produção de bens valorizados, aqueles que em nossos tempos são cultuados como símbolos da superação humana em relação ao próprio passado histórico - notadamente as descobertas científicas e inovações tecnológicas (Freitas, 2012). De acordo com Saffioti (1982), as indústrias de baixa densidade tecnológica, intensivas em trabalho, tendem a utilizar mão de obra feminina, enquanto as indústrias de alta sofisticação tecnológica, intensivas em capital, apresentam acentuada propensão a absorver maiores contingentes masculinos. Isso significa que maioria das mulheres integrantes do mercado de trabalho permanece vinculada a atividades identificadas como pré-capitalistas (Millet, 2000; Kon, 2006), a exemplo do trabalho fabril de baixo valor agregado, prestação de serviços e desempenho de atividades relacionadas à esfera doméstica.

A relação entre mulher e produção artesanal refere-se, portanto, ao baixo grau de sofisticação tecnológica da atividade, à associação entre o artesanato e os trabalhos domésticos "naturalmente" atribuídos às mulheres e à ideologia de que a mulher seria portadora de maior habilidade para o desempenho de tarefas minuciosas. Nas primeiras décadas da industrialização, quando as atividades fabris eram em grande medida artesanais, a maior parte do proletariado era constituída por mulheres, resignadas a salários inferiores em razão das estruturas sociais de dominação masculina. De modo geral, as mulheres trabalhavam nas indústrias que demandavam baixa mecanização, como fiação e tecelagem e ausentavam-se dos setores como metalurgia, calçados e mobiliário, ocupados pelos homens (Rago, 2006). Quando o Brasil realizou o seu primeiro censo, em 1872, a maior parte dos trabalhadores industriais eram mulheres - muitas delas empregadas na indústria têxtil que, no momento, era a mais importante do país (Saffioti, 1982). Apesar do elevado número de trabalhadoras presentes nos primeiros estabelecimentos fabris brasileiros, não se deve supor que elas asseguraram suas posições no mercado de trabalho; ao contrário. Entre os anos de 1900 e 1940, os censos evidenciam a queda da participação feminina na indústria, fato diretamente relacionado à desqualificação intelectual feminina e à intensificação dos processos mecanizados, em detrimento dos processos artesanais de produção (Saffioti, 1976).

Dados levantados por Saffioti (1982) em estudo sobre a evasão feminina na indústria demonstram que a transformação das empresas artesanais em empresas fabris modernas obrigou a mão de obra feminina a migrar para ocupações situadas à margem dos benefícios sociais implementados com a generalização das relações capitalistas de produção. Desde o século XIX, a maior parte da população feminina dedica-se a atividades vinculadas ao setor de serviços, especialmente aqueles ligados a atividades domésticas ou que envolvam, em alguma medida, um saber fazer artesanal (Soihet, 2006). Na década de 1970 , mais de $50 \%$ da população economicamente ativa feminina compunha "um imenso contingente de costureiras, bordadeiras, cerzideiras, tricoteiras, crocheteiras, para não dizer sobre as demais ocupações em caráter autônomo e de empregada doméstica" (Saffioti, 1982, p. 122). Nos anos 2000, 80\% das trabalhadoras brasileiras desempenhavam atividades vinculadas ao setor de serviços, sobretudo atividades domésticas remuneradas, então caracterizadas como "primeira ocupação das mulheres brasileiras" (Melo, 2005, p. 14). De acordo com dados divulgados pelo Programa de Artesanato Brasileiro (PAB) em 2009, entre os 8,5 milhões de brasileiros dedicados ao artesanato, $87 \%$ são mulheres.

A prevalência feminina denota que o artesanato no Brasil industrializado acabou se tornando refúgio para uma população desqualificada, marginal ao mercado de trabalho formal e, sobretudo, necessitada. A definição identitária da mulher-trabalhadora foi historicamente elaborada "em razão das conjunturas econômicas vividas" (Saffioti, 1976, p. 133). Por isso, a condição de trabalhadora decorre, principalmente, da necessidade de ganhar a vida ou colaborar com a renda da família, imposta pelo pertencimento às classes sociais desfavorecidas. Decorre que a subordinação da mulher na sociedade brasileira está inserida em uma relação dialética mais ampla, que abrange a tensão entre os impositores de uma determinada estrutura de poder e aqueles que resistem a ela. As questões concernentes à participação da mulher no mercado de trabalho brasileiro e a importância do artesanato como ocupação feminina não se restringem, portanto, à distribuição de poder entre os sexos, mas também evidenciam que a organização da família patriarcal como ideal hegemônico instituiu, na prática, a marginalização de formas de organização social alternativas ao padrão hegemônico. 


\section{Procedimentos Metodológicos}

É de relevância para o pesquisador identificar as tipologias utilizadas em pesquisas qualitativas, sobretudo aquelas usadas nos estudos organizacionais. Nesta pesquisa, utilizamos o estudo de caso que, conforme Godoy (1995, p. 25) "se caracteriza como um tipo de pesquisa cujo objeto é uma unidade que se analisa profundamente", visando-se "ao exame detalhado de um ambiente, de um simples sujeito ou de uma situação em particular".

Para a coleta de dados foram utilizadas duas técnicas de pesquisa: entrevistas semiestruturadas e observação direta. Os participantes das entrevistas foram dez rendeiras da Associação dos Morros da Mariana, contatadas intencionalmente e por acessibilidade. Essas rendeiras constituem os sujeitos da pesquisa e a quantidade de rendeiras participantes (ou seja, o universo da pesquisa) foi determinada pelo princípio da redundância ou saturação, ou seja, quando as respostas dadas não mais contribuíram para a elucidação do problema. Todas as entrevistas foram gravadas em meio digital e aconteceram entre o período de fevereiro a março de 2013. Em respeito ao anonimato dos sujeitos, suas falas serão seguidas pela palavra "Rendeira" e por numeral que varia entre 1 e 10, de acordo com a ordem em que foi realizada a entrevista.

A observação direta aconteceu durante dez visitas à Associação, cada uma com duração média de cinco horas. Segundo Yin (2005, p. 115), as observações diretas podem ser realizadas "ao longo da visita de campo, incluindo aquelas ocasiões durante as quais estão sendo coletadas outras evidências, como evidências provenientes de entrevistas". Seis visitas foram conduzidas entre fevereiro e março de 2013, na ocasião da realização das entrevistas, e outras quatro visitas foram realizadas entre março e abril de 2014, quando os dados previamente coletados e analisados foram apresentados às rendeiras da Associação e novas situações de campo puderam ser observadas pelos pesquisadores. Ambos os momentos foram oportunos para visualizar e captar aspectos que não necessariamente foram verbalizados durante a etapa das entrevistas.

A análise de dados seguiu a técnica da análise de conteúdo e sua vertente qualitativa (Bardin, 2012), e obedeceu às fases de pré-análise, na qual os dados foram lidos e relidos pelos pesquisadores; exploração do material, quando as falas de entrevistas e os relatos de observação foram pensados à luz dos constructos teóricos e realização de inferências e interpretações, com a construção de significados para as falas coletadas e práticas observadas. O corpus empírico analisado pela via da análise de conteúdo são as entrevistas transcritas e a validação dessa análise ficou condicionada aos dados de observação e as interpretações advindas da vivência das experiências de campo.

\section{Apresentação e Análise dos Dados}

Indústria caseira familiar comum no Brasil do século XIX, a renda de bilros que, na atualidade, é mais facilmente encontrada em comunidades do Nordeste do país e em Florianópolis, no estado de Santa Catarina, é feita pelo trançado de fios de algodão enrolados em pequenas peças de madeira, denominadas bilros, sobre uma almofada (Ferreira \& Lima, 2011). Daí ser também conhecida como renda de almofada, a que se fixa um molde, geralmente de papelão, chamado pique (Ferreira \& Lima, 2011). Conforme princípios vigentes em segmentos específicos da sociedade brasileira, podendo-se aí se situarem as comunidades rendeiras dos Morros da Mariana, a socialização de mulheres para o trabalho e para a vida se faz no seio familiar. Conforme Ferreira e Lima (2011), é pelas regras ditadas pelo comportamento das gerações mais velhas que se dá a formação das gerações mais novas: as meninas ajudam suas mães nas tarefas da casa. Assim, dividem seu tempo entre o estudo, o lazer e a brincadeira de fazer renda, reservando-se aos homens as atividades pesadas, como a agricultura e o extrativismo animal.

Na localidade de Morros da Mariana, no município de Ilha Grande, Piauí, distante cerca de 330 quilômetros da capital Teresina, a tradição da renda de bilro vem junto com os primeiros moradores. Em tempos antigos, na maneira de dizer das próprias rendeiras, por todas as ruas dali havia mulheres sentadas embaixo de árvores, na porta das casas, trançando os bilros nas suas almofadas. Os compradores que procuravam as delicadas rendas necessitavam andar de casa em casa e as rendeiras, muitas vezes, não conseguiam dar a atenção necessária aos visitantes devido às tarefas domésticas.

No início da década de 1990, a então primeira-dama do estado do Piauí, apreciadora das artes de renda de bilros, seguiu o movimento de apoio ao artesanato que se desenvolvia em muitos dos governos estaduais da época e incentivou as rendeiras da localidade de Ilha Grande a se reunirem em uma associação para concentrar a produção de renda em um só lugar e estimular as encomendas coletivas, beneficiando compradores e rendeiras. Dessa forma, nasceu no ano de 1992 a Associação das Rendeiras dos Morros da Mariana, com apoio técnico do SEBRAE para sua legalização. A construção da primeira sede da associação aconteceu em 1993 com apoio estadual. 
Desde então, a atividade passou a se firmar na economia das famílias das rendeiras. Em 1996, as rendeiras passaram legalmente a pertencer a uma associação, tendo como fins e objetivos no seu estatuto congregar a classe das rendeiras, em torno dos seus objetivos comuns, promovendo-se social e economicamente. A Associação é composta atualmente por cento e vinte artesãs que fizeram sua adesão espontaneamente. O quadro abaixo caracteriza o grupo de rendeiras entrevistadas quanto ao grau de escolaridade, a idade, ao estado civil e ao número de filhos.

Tabela 1:

Dados demográficos das artesãs

\begin{tabular}{|c|c|c|c|c|}
\hline Codificação & Escolaridade & Idade & $\begin{array}{c}\text { Estado } \\
\text { Civil }\end{array}$ & $\begin{array}{c}\mathbf{N}^{\circ} \text { de } \\
\text { Filhos }\end{array}$ \\
\hline Rendeira 1 & $\begin{array}{c}\text { Ensino fundamental } \\
\text { incompleto }\end{array}$ & 60 anos & Casada & 02 \\
\hline Rendeira 2 & $\begin{array}{c}\text { Ensino fundamental } \\
\text { incompleto }\end{array}$ & 40 anos & Casada & 02 \\
\hline Rendeira 3 & Ensino médio & 21 anos & Solteira & ----- \\
\hline Rendeira 4 & $\begin{array}{c}\text { Ensino fundamental } \\
\text { incompleto }\end{array}$ & 56 anos & Casada & 08 \\
\hline Rendeira 5 & Ensino médio & 37 anos & Casada & 03 \\
\hline Rendeira 6 & Ensino médio & 26 anos & Solteira & ---- \\
\hline Rendeira 7 & $\begin{array}{c}\text { Ensino fundamental } \\
\text { incompleto }\end{array}$ & 44 anos & Divorciada & 03 \\
\hline Rendeira 8 & $\begin{array}{c}\text { Ensino fundamental } \\
\text { incompleto }\end{array}$ & 56 anos & Viúva & 06 \\
\hline Rendeira 9 & Ensino superior & 24 anos & Casada & ----- \\
\hline Rendeira 10 & Ensino médio & 27 anos & Casada & 01 \\
\hline
\end{tabular}

Nota. Fonte: Dados da pesquisa.

Na cidade de llha Grande, a renda de bilros é considerada uma forte indústria caseira, pois mesmo existindo a Associação das Rendeiras, este trabalho ainda é exercido (de forma geral) nas casas das mulheres da cidade. Como tradição cultural, a atividade rendeira sempre esteve ligada à estrutura familiar pela ação da mulher, complementando a priori o trabalho masculino da pesca artesanal. O fato da comercialização da produção rendeira ser recente - iniciado na década de 1990 - indica que a atividade tivesse sido anteriormente desenvolvida no âmbito privado, como ocupação feminina relacionada às práticas domésticas. A longa e silenciosa história das "artes domésticas" (Adamson, 2008) assinala o caráter discreto e passivo das atividades desempenhadas por mulheres, assim como condiciona a suposta valorização do labor desprendido na esfera privada à situação de invisibilidade do trabalho feminino na esfera pública.

Isso porque, ainda que o trabalho artesanal sempre tenha feito parte das atribuições femininas, as produções materiais relacionadas às mulheres foram percebidas como repetição do ciclo ancestral da geração e manutenção da vida e, portanto, indignas de notabilidade na historiografia masculina. É por isso que, até hoje, entre as rendeiras da llha Grande, é comum a percepção de que o trabalho artesanal feminino é subsidiário ao trabalho masculino. Isso se reproduz na fala transcrita abaixo, em que transparece como a Rendeira 10 percebe sua atividade profissional como complementar ao trabalho dos maridos:

A gente tira um trocadinho até bom. A venda da renda me ajuda, ajuda e muito nas despesas de casa, [ porque] na despesa de casa não espero só pelo meu marido. (Rendeira 10).

Com a elaboração e comercialização das peças rendadas, as mulheres contribuem significativamente no orçamento familiar, ainda que sua atividade profissional seja tratada pela comunidade em questão como suplementar da renda auferida pelos homens chefes de família. Para algumas delas, porém, o trabalho artesanal na renda é fonte principal de sustento. Isso revela um aspecto pouco problematizado a respeito da atividade empreendedora feminina: a necessidade de analisar a ação empreendedora da mulher a partir de um viés crítico das questões de gênero e classe social. No que diz respeito às possibilidades de empreender na atividade artesanal, mormente se percebe que algumas rendeiras correspondem ao que Safiotti (1982) define como "mulheres necessitadas", que trabalham porque se encontram em certa situação de vulnerabilidade econômica provocada pela ausência de uma figura masculina que faça as vezes de provedor doméstico ou pela impossibilidade de acesso a outras formas de capital capazes de garantir a emancipação feminina, como por exemplo, a educação. O trecho de entrevista transcrito a seguir expressa o sentido da necessidade na perspectiva de uma rendeira e dá conta de um grau aprofundado de dependência em relação ao trabalho artesanal da renda: 
O que vou fazendo aqui na Associação é para me manter, porque eu moro em uma casa separada da minha mãe, minha mãe mora na frente e eu moro no fundo da casa dela. Se não fosse este meu serviço aqui eu não sei o que seria de mim, mas às vezes a gente sobrevive, quem tem coragem de trabalhar não passa necessidade, não passa nada, porque procura outro meio de vida para sobreviver, mas eu gosto do meu serviço e é isso aqui que sei fazer de melhor (Rendeira 7).

É fato digno de nota que a fala supracitada exprima o desamparo da rendeira que não saberia o que fazer para sobreviver se não trabalhasse no artesanato de renda. Nesse sentido, a atividade empreendedora se relaciona à extrema falta de oportunidades que faz com que a renda seja o que as rendeiras dos Morros da Mariana saibam fazer de melhor e que possam, a partir disso, elaborar um meio de vida para sobreviver. A coragem, definida em muitos manuais de empreendedorismo como característica fundamental do empreendedor - por estar ligada ao ímpeto para a exploração de novas oportunidades e a capacidade de lidar com o risco (Shane, 2003) - é o imperativo que move muitas empreendedoras que precisam enfrentar os desafios da sobrevivência a partir de um lugar novo para as mulheres submetidas às regras do sistema patriarcal. Apesar disso, nota-se que o termo "coragem" se refere à "necessidade" e indica como é aviltante a situação da mulher sozinha e desqualificada que precisa trabalhar para sobreviver.

Sobre a questão do empreendedorismo por necessidade, que emerge das falas analisadas anteriormente, convém mencionar que usualmente, as definições de empreendedorismo enfatizam a ação empreendedora na relação com o mercado, posto que a atividade capitalista está no cerne da ideia de entrepreneur, tal como aparece nos escritos de Schumpeter (1988). Numa perspectiva que abriga uma perspectiva social, autores contemporâneos falam a respeito da ação empreendedora como a criação do novo, podendo ser orientada para diferentes processos sociais de mudança, que vão muito além da orientação para criar valor econômico e que almejam a emancipação (Rindova, Barry \& Ketchen, 2009; Goss, Jones \& Beta, 2011).

Para os autores (Rindova, Barry \& Ketchen, 2009), o impulso empreendedor se realiza na busca de oportunidades e no esforço para superar ou remover restrições que podem ser de natureza intelectual, psicológica e de caráter econômico, social, institucional, ou cultural. Nesse sentido, ao ver ação empreendedora como a criação de mudança através da superação de restrições, Rindova, Barry e Ketchen (2009) se relacionam com a ideia da necessidade, impulsionando processos empreendedores. Todavia, convém mencionar que a proposta de Rindova, Barry e Ketchen (2009) está relacionada a um sentido mais amplo e aprofundado de mudança, que ultrapassa os horizontes da vida de um indivíduo e se transformam em potências emancipadoras para um conjunto maior de pessoas. Isso fica justificado quando os autores recorrem ao conceito de empreendedorismo social para explicar como a emancipação pode ser conquistada (Rindova, Barry \& Ketchen, 2009). Sendo assim, a mudança de vida que o artesanato pode provocar para cada uma das mulheres necessitadas, que se vincula à atividade, não é suficiente para subverter o status de inferioridade de poder que as acomete no contexto societário mais amplo.

Considerando a emancipação como um ato de liberdade em relação ao outro, por meio do encontro de oportunidades (Goss, Jones \& Beta, 2011), temos que o trabalho na Associação pode assegurar a reprodução da subsistência - algo que não podia não ser conseguido pelas artesãs de outro modo - mas não contribui para desarticular relações de dependência de gênero mais aprofundadas, que continuarão a produzir mulheres necessitadas dentro daquele mesmo contexto social. Disso decorre o fato de que a indenpendência financeira conquistada por algumas artesãs pela via do empreendedorismo no artesanato é legítima, mas nos leva a reinterpretar os pressupostos de Rindova, Barry e Ketchen (2009) e entender que o empreendedorismo pode gerar uma variedade de mudanças sociais e que nem todas elas podem ser chamadas de emancipação (Calas, Smircich \& Bourne, 2009). Isso porque a dinâmica do poder não é subvertida pela prática empreendedora em questão (Goss, Jones \& Beta, 2011).

Numa outra análise, ao descrever a atividade rendeira como "o que sabe fazer de melhor", a Rendeira 7 deixa transparecer um outro aspecto passível de crítica no que diz respeito à vinculação entre empreendedorismo feminino e artesanato: o fato de que muitas mulheres no Brasil contemporâneo ainda têm as prendas domésticas como única especialização. No Brasil, as mulheres foram tradicionalmente treinadas em práticas culturalmente transmitidas e costumam, até hoje, ter incentivo da família e demais instituições sociais responsáveis pela socialização feminina para incorporarem habilidades associadas às artes, aos trabalhos artesanais e à manutenção do lar. No seio da família patriarcal, as mulheres de todas as classes sociais foram, durante décadas, (e, em alguma medida, continuam sendo) incentivadas a especializarem-se em prendas domésticas que pudessem Ihes conferir o status de "moças prendadas", bem-dotadas para o "mercado casamenteiro e para cumprir seu destino biológico" (Lamas, 2007, p. 85). A fala da rendeira 3, transcrita a seguir, dá conta de como o artesanato de renda fez parte da educação doméstica das mulheres da 
localidade dos Morros da Mariana e também como este saber se configurou como oportunidade profissional para algumas delas:

Eu entrei na associação porque minha avó era associada, ela fazia renda aí eu me interessei pelo trabalho e vim pra cá para a associação, eu estou na associação desde 2011. Minha avó me ensinou renda eu tinha 7 anos, eu achava bonito ela fazendo e aí eu ficava mexendo na almofada dela, e aí ela colocou uma almofada pra mim e desde aí pronto, eu estudava durante o dia mas à noite eu fazia renda. A oportunidade de entrar no negócio de renda e aprender começou com minha avó (Rendeira 3).

A fala acima pode ser lida em perspectiva com uma análise sobre a educação formal feminina. Isso porque, historicamente, a ideologia da superioridade masculina e da hegemonia dos homens no ambiente público mantiveram as mulheres aprisionadas a "funções ligadas à reprodução física e social do grupo, impedindo-as de desenvolverem e descobrirem suas verdadeiras potencialidades e competências tanto na esfera pública quanto na sociedade civil" (Barbosa, 2012, p. 179). Contemporaneamente, as mulheres pertencentes às camadas mais favorecidas da sociedade passaram a ter maiores chances de conquistar a independência em relação às formas tradicionais de educação feminina. Isso porque seu acesso ao sistema de educação formal, que pressupõe a universalização do acesso aos saberes, possibilita que acumulem capital cultural e assegurem para si certas formas de especialização profissional valorizadas no mercado de trabalho. Já as mulheres pertencentes às camadas menos favorecidas têm contra si o peso de um sistema educacional excludente, que cria barreiras virtuais para as escolhas profissionais das mulheres mais pobres.

Sem nenhuma formação legítima - já que o mundo do trabalho contemporâneo exige a profissionalização enquanto requisito legitimador do trabalhador - muitas mulheres de baixa renda acabam tendo como única opção desempenhar atividades relacionadas a essa formação feminina tradicional. Isso explica por que $17 \%$ das mulheres que trabalham no Brasil realizam trabalhos domésticos (OIT, 2013) e também por que muitas outras veem no artesanato a única alternativa possível para o desempenho da atividade empreendedora. Não é por acaso, portanto, que $87 \%$ dos artesãos brasileiros sejam mulheres $(P A B, 2010)$ e que a maior parte dos empreendimentos femininos no mundo ainda esteja vinculada a ocupações femininas tradicionais (Anna, Chandler, Jansen \& Mero, 2000). Em relação ao que estamos dizendo, convém mencionar que metade das dez rendeiras entrevistadas tinha ensino fundamental incompleto, outras quatro haviam completado o ensino médio e apenas uma chegou a concluir o ensino superior.

Ainda em relação ao trabalho doméstico, outra questão que chama atenção é a vinculação entre a mulher, o espaço da casa e o artesanato e a maneira como a carreira feminina no empreendimento artesanal pode estar baseada na supressão da ação feminina na esfera pública. Por muito tempo, diz Adamson (2008, p. 140), "o artesanato amador foi um assunto privado domínio exclusivo de mulheres abastadas e, particularmente, aristocráticas, que dedicavam seu tempo a 'realizações' tais como tecelagem, bordado e pintura decorativa", que embora pudessem ser apreciadas por suas qualidades técnicas e estéticas, comparáveis ao artesanato profissional e mesmo à arte, eram desqualificadas em razão da forte conotação doméstica que carregavam (Adamson, 2008).

As atividades artesanais desenvolvidas por um grande número de mulheres amadoras trabalhando em meios desvalorizados segundo os padrões da arte patriarcal confirmavam a visão burguesa de que homens e mulheres teriam sensibilidades e capacidades intelectuais diferentes (Chadwich, 1991), e que a produção delas necessariamente confirmaria "a beleza, a graça, a modéstia e a frivolidade" (Chadwich, 1991, p. 127) inerentes ao feminino. A naturalização de certas características como inerentes ao ser feminino contribui para vincular a atividade artesanal às mulheres e, de maneira subliminar, a condicionar o empreendedorismo feminino no artesanato ao espaço da casa. A fala da Rendeira 1, transcrita a seguir, ilustra a dificuldade que muitas mulheresartesãs sentem em se desprender do espaço doméstico a medida em que a atividade artesanal se profissionaliza:

A gente achou meio ruim no início a ideia de sair de casa [ para trabalhar na Associação] porque ninguém tinha costume, e a casa das rendeiras era muito pequena não tinha banco, a gente começou todo mundo trazia sua cadeira de casa, a casa era muito pequena só tinha uma porta de entrada e uma janela, era uma coisa muito pequena, mas a gente conseguiu ficar assim mesmo (Rendeira 1 ).

$\mathrm{Na}$ análise das falas das rendeiras entrevistadas, outro ponto digno de nota é vinculação entre o trabalho feminino e a maternidade, que também se faz perceber no campo empírico da Associação das Rendeiras dos Morros da Mariana, posto a recorrência da menção ao cuidado com a família e a atenção aos filhos também se apresenta como entrave ou como estímulo para a atividade empreendedora. A participação ativa da mulher na esfera pública implica assumir responsabilidades que, na maioria das vezes, se acumulam com aquelas tradicionalmente imputadas às mulheres no 
cuidado do lar e da família. Empreender como um ato de coragem, para as mulheres, também diz respeito a desafiar as barreiras invisíveis que a sociedade patriarcal impõe ao trabalho feminino na esfera pública, chamadas no jargão dos estudos de gênero como glass ceiling e que também se impõe como obstáculo para o empreendedorismo (Morrison, White \& Van Velsor, 1987; Moore \& Butner, 1997; Godwin, Stevens \& Brenner, 2006). A fala de outra entrevistada, transcrita a seguir, esclarece como o cuidado com os filhos é uma barreira para a atividade empreendedora.

Eu comecei aqui em 2002 quando vim para a associação e até hoje estou aqui, eu já fazia renda em casa, mas foi o tempo que eu casei, tive minhas filhas e aí tive que trabalhar em casa, a oportunidade de entrar no negócio das rendas, de vim pra associação era porque eu trabalhava ao lado da associação e eu tinha muita vontade de trabalhar, mas aí não podia por causa das filhas pequenas, mas quando foi no tempo certo eu vim e comecei trabalhar aqui na associação. (Rendeira 2).

Certa promiscuidade entre o espaço do trabalho e o espaço da casa, fomentada pelas formas de socialização feminina e pelas alternativas profissionais que lhes são concedidas corroboram com certos preconceitos culturais. Simião (2013) refere-se, por exemplo, à imagem de grupo empreendedor feminino como um grupo de mulheres que se juntam para conversar, como se a atividade que desempenham fosse uma maneira de passar o tempo, apesar de desenvolverem uma atividade que acaba tendo como resultado algum objetivo econômico. Esse preconceito do senso comum é reforçado, no que diz respeito ao empreendedorismo feminino no artesanato, já que as práticas artesanais são fortemente vinculadas ao diletantismo, à distração e a uma forma de trabalho que não se podia considerar séria. No tocante à mesma questão, a associação entre o trabalho artesanal feminino e as atividades domésticas contribui para a percepção generalizada de que esta é uma atividade pouco profissional, destinada a mulheres pouco competentes. A consequência direta dessa forma de pensar é a baixa valorização do trabalho artesanal, que é, de modo geral, mal remunerado.

\section{Conclusões e Recomendações}

Neste artigo, a proposta foi discutir a questão da profissionalização de uma atividade artesanal amadora, identificada com a reprodução das identidades sociais de gênero e classe de um grupo específico de mulheres. O objetivo foi problematizar o empreendedorismo feminino a partir de uma perspectiva crítica, subsidiada por teorias feministas que tomam por princípio a relação entre trabalho e práticas sociais. Procurou-se compreender como o artesanato feminino tradicionalmente desempenhado na esfera doméstica adentra o espaço público e é incorporado ao sistema capitalista enquanto empreendimento comercial. Para isso, trataram-se aspectos concernentes à relação entre mulher e produção artesanal.

Na análise, não houve a intenção de enfocar tanto as formas como a carência de formação especializada como sendo imposta às mulheres através de barreiras sistemáticas ao acesso ao sistema educacional, nem como a clivagem de classe social contribui para estreitar ainda mais as possibilidades de escolha profissional da mulher pobre, ainda que essas questões sejam importantes para uma análise crítica do fenômeno do empreendedorismo feminino no Brasil. O que se quis chamar atenção foi para o fato de que a definição clássica de empreendedorismo, relacionada à ideia de desenvolvimento econômico, preceitua como ações inovadoras podem introduzir descontinuidades e provocar revoluções na economia (Schumpeter, 1983).

Sabe-se que, na economia contemporânea, essas inovações estão muito relacionadas ao desenvolvimento tecnológico. Sabe-se, também, que a participação das mulheres no setor de alta tecnologia tem crescido (Jonathan, 2003), mas é importante lançar luz sobre os processos que subjazem essa mudança. As análises desenvolvidas nesse artigo indicam que há uma barreira invisível que diminui a importância da atividade empreendedora feminina para o resultado geral da economia. Essa barreira tem três lastros principais: a necessidade de se manter a desigualdade de poder de gênero, que faz com que a ação empreendedora feminina seja considerada menos importante para a geração de renda que a masculina; a dificuldade de acesso das mulheres às carreiras voltadas para a produção de conhecimento-base para o desenvolvimento tecnológico (que se agrava quando se considera essa questão a partir de uma perspectiva de gênero matizado por diferenças sociais); e a naturalização dos papeis de gênero que, em muitos casos, obrigam as mulheres a empreenderem em atividades que são tradicionalmente consideradas "domínios femininos". Não por acaso, essas atividades são pouco valorizadas e, consequentemente, mal remuneradas.

Através de fragmentos da narrativa das rendeiras entrevistadas, foi possível identificar que a profissionalização de uma atividade artesanal considerada "amadora" não se faz sem impasses e conflitos. Por um lado, a exposição da mulher na esfera pública através da ação empreendedora 
provoca instabilidade no sistema patriarcal, cujas características concretas e ideais serviram de anteparo para forjar a identidade feminina hegemônica e são frequentes as tentativas masculinas de impedir que as carreiras femininas se desenvolvam e almejem sucesso. Isso implica que o delinear de um projeto profissional, a partir de uma prática costumeiramente identificada com a produção doméstica de consumo familiar, requer que a mulher desconstrua os padrões de comportamento esperados e estabeleça novos vínculos com o espaço público. Por outro lado, quando o artesanato feminino ganha notoriedade e se torna amplamente reconhecido, é comum que seja convertido em empreendimento comercial.

Ainda que a produção e comercialização da renda de bilro sejam fontes geradoras de recursos financeiros para o grupo de mulheres da Associação de Rendeiras dos Morros da Mariana, o que se pode perceber através deste estudo é que a atividade empreendedora baseada no artesanato não é uma ação emancipatória, capaz de subverter a desigual distribuição de poder (nesse caso, econômico) entre os homens e mulheres na sociedade em questão. Ainda que empreendedorismo possa ser pensado como princípio para emancipação (Rindova; Barry; Ketchen, 2009), posto que a ação empreendedora é criação de mudança por meio da superação de restrições, a prevalência de uma normatividade do gênero masculino no empreendedorismo denuncia a manutenção da tradicional divisão sexual do trabalho, o que é incompatível com o ideal da emancipação (Goss, Jones \& Beta, 2011). Parafraseando Colling (2004, p. 13) que afirma: "foi necessária muita criatividade para inventar a mulher como sujeito autônomo", concluímos que será preciso muita criatividade para que o empreendedorismo feminino - especialmente aquele fundamentado em atividades tradicionalmente associadas com os fazeres femininos - consiga se desenvolver de forma autônoma.

Assim, a ideia de que o empreendedorismo no artesanato praticado por mulheres poderia promover a emancipação é uma contradição de termos porque a atividade, tal como é desenvolvida no contexto estudado, serve tão somente para ocupar mulheres em atividades não muito diferentes ou distantes daquelas desenvolvidas na esfera doméstica. A contradição, que buscamos expor por meio de uma análise crítica, é que o artesanato tradicionalmente identificado com a divisão do sexual do trabalho, no caso da Associação de Rendeiras dos Morros da Mariana, não chega a ser ressignificada como uma prática de resistência ao poder patriarcal.

Como recomendação para pesquisas futuras, sugerimos que a questão da emancipação continue a ser discutida no âmbito do empreendedorismo, especialmente no que diz respeito a uma abordagem de gênero sobre a proposta de empreendedorismo como mudança social (Calas, Smircich \& Bourne, 2009), mas também em abordagens que enfatizem outros aspectos da diversidade que contribuam para dar nuances mais plurais ao fenômeno do empreendedorismo. Segundo a linha dos achados deste estudo, propomos que outras pesquisas examinem as possíveis relações de poder e gênero ao tomarem como objeto de investigação atividades artesanais que se tornam base para iniciativas empreendedoras. Para estender ou se contrapor aos achados aqui apresentados, seria particularmente interessante estudar atividades artesanais que não são identificadas como femininas na tradicional divisão sexual do trabalho, como o artesanato de barro, por exemplo. Nelas, a questão da subalternidade do artesanato no contexto da produção contemporânea persiste, mas uma vivência diferente das relações de poder ligadas às questões de gênero pode oferecer outra perspectiva acerca das possibilidades de emancipação.

\section{Notas}

1. Agradecemos aos avaliadores anônimos que contribuíram com seus pareceres para a melhoria do texto original.

\section{Referências}

Anna, A., Chandler, G., Jansen, E., \& Mero, N. (2000). Woman business owners in traditional and nontraditional industries. Journal of Business Venturing, 15(3), 279-303.

Adamson, G. (2008). Thinking through craft. Oxford: Berg.

Arendt, H. (2009). A condição humana (10 Ed.) Rio de Janeiro: Forense Universitária.

Badinter, E. (1985). Um amor conquistado: o mito do amor materno. Rio de Janeiro: Nova Fronteira.

Barbosa, L. (2012). Os donos e as donas da cozinha. In M. E. Freitas, \& M. Dantas (Orgs). Diversidade sexual e trabalho (pp. 171-201). São Paulo: Cenage Learning.

Bardin, L. (2012). Análise de Conteúdo. São Paulo: Edições 70. 
Bird, B., \& Brush, C. (2002). A gendered perspective on organizational creation. Entrepreneurship Theory and Practice, 26(3), 41-65.

Blake, M. K., \& Hanson, S. (2005). Rethinking innovation: Context and gender. Environment and Planning A, 37(4), 681-701.

Brush, C. G. (1992). Research on women business owners: Past trends, a new perspective and future directions. Entrepreneurship Theory and Practice, 16(4), 5-31.

Busenitz, L. W., West, G. P., Shepherd, D., Nelson, T., Chandler, G. N., \& Zacharakis, A. (2003). Entrepreneurship research in emergence: Past trends and future directions. Journal of Management, 29(3), 285-308.

Calás, M. B., \& Smircich, L. (2006). Do ponto de vista da mulher: abordagens feministas em estudos organizacionais. In S. R. Clegg, C. Hardy, \& W. R. Nord (Orgs.). Handbook de estudos organizacionais: modelos de análise e novas questões em estudos organizacionais (pp. 273-327). São Paulo: Atlas.

Calás, M. B., Smircich, L., \& Bourne, K. A. (2007). Knowing Lisa? Feminist analyses of gender and entrepreneurship. In D. Bilimoria \& S. K. Piderit (Orgs.). Handbook on women in business and management (pp. 78-105). Cheltenham: Edward Elgar.

Calás, M. B., Smircich, L., \& Bourne, K. (2009). Extending the boundaries: Reframing "entrepreneurship as social change" through feminist perspectives. Academy of Management Review, 34(3), 552-569.

Cassol, N., Silveira, A., \& Hoeltgebaum, M. (2007). Empreendedorismo feminino: análise da produção científica da base de dados do Institute for scientific information (ISI), 1997-2006. Anais do Encontro da ANPAD, Rio de Janeiro, RJ, Brasil, 31.

Chadwick, W. (1991). Woman, art, and society. London: Thames and Hudson.

Colling, A. (2004). A construção histórica do feminino e do masculino. In M N. Strey, S. Cabeda, \& D. Prehn (Orgs). Gênero e cultura: questões contemporâneas (pp. 13-38). Porto Alegre: EDIPUC.

Donzelot, J. (1986). Polícia das famílias. Rio de Janeiro: Graal.

Ferreira, T., \& Lima, R. (2011). Morros da Mariana: um espaço rendado. Rio de Janeiro: IPHAN, CNFCP.

Fine, B. (1992). Women's employment and the capitalist family. London: Routledge.

Fischer, T., \& Soares, R. M. (2012). Maestria em artes e ofícios populares: uma questão de gênero. In M. E. Freitas \& M. Dantas (Orgs). Diversidade sexual e trabalho (pp. 312-335). São Paulo: Cenage Learning.

Freitas, M. E. (2012). O sexo do trabalho intelectual. In M. E. Freitas \& M. Dantas (Orgs). Diversidade sexual e trabalho (pp. 203-235). São Paulo: Cenage Learning.

Godoy, A. (1995). Pesquisa qualitativa: Tipos Fundamentais. Revista de Administração de Empresas, $35(3), 20-29$.

Godwin, L. N., Stevens, C. E., \& Brenner, N. L. (2006). Forced to play by the rules? Theorizing how mixed-sex founding teams benefit women entrepreneurs in male-dominated contexts.

Entrepreneurship Theory and Practice, 30(5), 623-642.

Goss, D., Jones, R., Betta, M., \& Latham, J. (2011). Power as practice: A micro-sociological analysis of the dynamics of emancipatory entrepreneurship. Organization Studies, 32(2), 211-229.

Hisrich, R., \& Peters, M. Empreendedorismo (5 ed). São Paulo: Artmed, 2005.

Holmstrom, N. (Ed.). (2002). The socialist feminist project: A contemporary reader in theory and politics. New York: Monthly Review Press.

Hurley, A. E. (1999) Incorporating feminist theories into sociological theories of entrepreneurship. Women in Management Review, 14(2), 54-62.

Jonathan, E. (2003). Empreendedorismo feminino no setor tecnológico brasileiro: dificuldades e tendências. Anais do Encontro de Empreendedorismo e Gestão de Pequenas Empresas, Brasília, DF, Brasil, 3.

Kon, A. (2006). Segmentação e informalidade do trabalho nas empresas, uma perspectiva de gênero. Mulher e Trabalho, 6, 41-57.

Lamas, B. (2007). As artistas: recortes do feminino no mundo das artes. Porto Alegre: Artes e Ofícios. 
Lewis, P. (2006). The quest for invisibility: Female entrepreneurship and the masculine norm of entrepreneurship. Gender, Work and Organization, 13(5), 453-468.

Macedo, K. B., Caixeta, C., Guimarães, D. C., Macedo, G., \& Hernandez, J. (2004). O processo sucessório em organizações familiares e a exclusão da mulher. Psicologia \& Sociedade, 16(3), 69-81. Machado, H. (2009). Identidade de mulheres empreendedoras. Maringá: Eduem.

Marquesan, F., \& Figueiredo, M. (2014). De artesão a empreendedor: a ressignificação do trabalho artesanal como estratégia para a reprodução de relações desiguais de poder. Revista de Administração Mackenzie, 15(6), 76-97.

Menezes, R., \& Bertucci, J. O. (2009). Mulher de negócios: uma análise da representação social com base no discurso de Empresárias associadas à Business Professional Women. Anais do Encontro da AnPAD, Rio de Janeiro, RJ, Brasil, 33.

Millet, K. (2000). Sexual politics (5 ed). New York: Doubleday \& Co.

Mirchandani, K. (1999). Feminist insight on gendered work: New directions in research on women and entrepreneurship. Gender, Work and Organization, 6(4), 224-235.

Moore, D., \& Buttner, E. (1997). Women Entrepreneurs. London: Sage Publications.

Morrison, A., White, R., \& Van Velsor, E. (1987). Breaking the glass ceiling: Can women reach the top of America's largest corporations? Reading: Addison-Wesley.

Moura, S. M., \& Araujo, M. F. (2005). A maternidade na história e a história dos cuidados maternos. Psicologia, Ciência e Profissão, 24(1), 44-55.

Munhoz, G. (2000). Quais as contribuições que o estilo feminino de liderança traz para as organizações empreendedoras? Anais do Encontro Nacional de Empreendedorismo, Maringá, PR, Brasil, 1, 164-176.

Nunes, J. (2006). O empreendedorismo feminino e o estilo de liderança no Conselho da Mulher empreendedora da associação comercial de Minas Gerais. Dissertação de Mestrado, Faculdade de Estudos Administrativos, Belo Horizonte, MG, Brasil.

Organização Internacional do Trabalho. (2013). Panorama Geral do Trabalho Doméstico, no Brasil e no mundo. Relatório da OIT.

Programa do Artesanato Brasileiro. (2010). Glossário do Programa Do Artesanato Brasileiro - Base Conceitual. Brasília: Ministério do Desenvolvimento, Indústria e Comércio Exterior.

Melo, H. P. de. (2005). Gênero e pobreza no Brasil: relatório nal do Projeto Governabilidad Democratica de Género en America Latina y el Caribe. Brasília: Cepal, SPM.

Rago, M. (2006). Trabalho feminino e sexualidade. In M. Del Priore (Org.). História das mulheres no Brasil (8 ed.) (pp. 578-605). São Paulo: Contexto.

Rees, T. (1992). Woman and the labor market. London: Routledge.

Rindova, V., Barry, D., \& Ketchen Jr., D. (2009). Introduction to special topic forum: entrepreneuring as emancipation. Academy of Management Review, 34(3), 477-491.

Schumpeter, J. (1983). Teoria do desenvolvimento econômico. São Paulo: Abril Cultural.

Saffioti, H. (1976). Trabalho feminino e capitalismo. Perspectivas, 1, 119-163.

Saffioti, H. (1982). O trabalho da mulher no Brasil. Perspectivas, 5, 115-135.

Saffioti, H. (1985). Força de trabalho feminina no Brasil: no interior das cifras. Perspectivas, 8, 95141.

Sennett, R. (2008). O artífice. São Paulo: Record.

Simião, S. D. (2013). As coisas fora do lugar. Gênero e o potencial de programas de geração de emprego e renda. Recuperado em 29 maio, 2013, de

http://www.redemulher.org.br/generoweb/daniel.htm.

Shane, S. (2003). General Theory of Entrepreneurship: the individual-opportunity nexus. Northampton: Edward Elgar.

Soihet, R. (2006). Mulheres pobres e violência no Brasil urbano. In M. Del Priore (Org.). História das mulheres no Brasil (8 ed.) (pp. 362-399). São Paulo: Contexto.

Yin, R. (2005). Estudo de caso: planejamento e métodos (3 Ed.). Porto Alegre: Bookman. 